\title{
PIONEIRISMO FEMININO NA FACULDADE DE DIREITO DO RECIFE: AS PRIMEIRAS BACHARELAS EM DIREITO DO BRASIL
}

\author{
FEMALE PIONEERING AT THE FACULTY OF LAW OF RECIFE: THE FIRST \\ WOMEN TO GRADUATE IN LAW IN BRAZIL
}

Recebimento em 09/02/2021

Aceito em 09/09/2021

\author{
Humberto João Carneiro Filho ${ }^{1}$ \\ Manoela Antunes Chagas de Souza ${ }^{2}$ \\ Elizabeth da Silva Guimarães ${ }^{3}$
}

\section{RESUMO}

Este artigo propõe um resgate histórico da presença feminina no ensino superior brasileiro, com ênfase nas primeiras bacharelas da Faculdade de Direito do Recife. Analisa a contribuição de Tobias Barreto de Menezes na defesa da emancipação feminina através da educação, quando foi parlamentar na Assembleia Provincial de Pernambuco. Ainda, busca conhecer as trajetórias estudantil e profissional das primeiras mulheres formadas na Faculdade de Direito do Recife e identificar possíveis contribuições suas no contexto social da época em que viveram. Para tanto, adota como metodologia a pesquisa exploratória a partir da revisão do trabalho historiográfico de Gláucio Veiga, com o cotejo do acervo disponível no Arquivo da Faculdade de Direito do Recife e no acervo hemerográfico da época. Verifica que conquanto as quatro discentes pioneiras no ensino jurídico brasileiro serem destacadas por seus méritos acadêmicos, não se efetivaram no exercício da profissão, dentre outras razões, pela resistência da sociedade da época em admitir mulheres em ambientes de atuação profissional. Ainda assim, e de alguma forma em resposta a isto, algumas delas se fizeram ouvir através da imprensa daépoca, em defesa da maior participação das mulheres na vida política, social e cultural.

Palavras-chaves: Educação da mulher. Ensino Superior. Direito. Escola do Recife.

\section{ABSTRACT}

This article presents a historical review of the female representation in Brazilian higher education, with an emphasis on the trajectory of the first women to obtain a law degree at the Faculty of Law of Recife. It analyzes the contribution of Tobias Barreto de Menezes in defense of the women's emancipation through education when he was a parliamentarian in the Provincial Assembly of Pernambuco. It also seeks to know the educational and professional trajectories of the first women graduated at the Faculty of Law of Recife and to identify possible contributions of their own in the social context of the time in which they lived. Therefore, it adopts an exploratory research as a methodology based on the review of the historiographic work of Gláucio Veiga, through the collection available in the Archives of the Faculty of Law of Recife and in the hemerographic collection of the time. It verifies that while the four pioneer students in Brazilian legal education are highlighted for their academic merits, they were not effective in the profession, among other reasons, due to the resistance of the society of the time in admitting women in professional environments. Still, and somehow in response to this, some of them made themselves

${ }^{1}$ Professor do Departamento de Teoria Geral do Direito e Direito Privado. Coordenador do Projeto Memória Acadêmica da Faculdade de Direito do Recife.

${ }^{2}$ Graduada em Biblioteconomia pela Universidade Federal de Pernambuco (CAC/UFPE). Extensionista do Projeto Memória Acadêmica da Faculdade de Direito do Recife.

${ }^{3}$ Graduanda em Direito pela Faculdade de Direito do Recife da Universidade Federal de Pernambuco (FDR/UFPE). Extensionista do Projeto Memória Acadêmica da Faculdade de Direito do Recife. 
heard through the press of the time, in defense of the greater participation of women in political, social and cultural life.

Keywords: Women Education. Higher Education. Law. School of Recife.

\section{INTRODUÇÃO}

As aspirações brasileiras para fundação de um estabelecimento de ensino superior no Brasil remontam aos tempos coloniais (BEVILÁQUA, 2012). Diversamente da experiência na América Espanhola - que possuía numerosas instituições de formação superior desde 1538 - o Brasil apenas contou com os seus primeiros cursos superiores a partir de 1808 , no contexto das iniciativas de promoção cultural empreendidas por Dom João IV, transferida que fora a sede do poder metropolitano para o Rio de Janeiro. Isto denota que não parecia interessante a Portugal estimular o desenvolvimento do ensino superior em terras brasileiras (CUNHA, 2007; CARVALHO, 2008).

Os cursos de ciências sociais e de ensino jurídico não foram contemplados no processo de mudança cultural empreendido no início do século XIX. Toda a gama de profissionais e intelectuais com formação jurídica continuava a advir da Europa - em especial de Portugal -, assumindo ativa participação na vida política brasileira mesmo após a independência ocorrida em 1822, como frisado por Carvalho (2008), ao destacar que até 1850 a maioria dos membros da elite brasileira aind a se compunha de pessoas formad as na Universidade de Coimbra.

Tal cenário, no entanto, tornou-se insustentável em um Brasil pós-independência, no qual a ereção de uma escola de direito formalmente autônoma daquela portuguesa e centrada no ordenamento jurídico pátrio corresponderia à imperiosa necessidade do país de estruturar sua própria elite administrativa, conhecedora das especificidades jurídicas e burocráticas atinentes ao estado recém-emancipad o, embora substancialmente não tão distante dos paradigmas europeus.

Assim, na Assembleia Geral Constituinte e Legislativa de 1823, após a instauração do Império no Brasil, surgiram debates a respeito da criação das primeiras universidades. Em 19 de agosto de 1823, foi apresentado um projeto e aprovado com emenda de Araújo Lima, visando ao estabelecimento de duas universidades: uma em São Paulo e outra em Olinda, e nelas os cursos jurídicos. Tal iniciativa, entretanto, não prosperou em razão da dissolução da Assembleia Constituinte por Dom Pedro I em novembro de 1823.

Em 9 de janeiro de 1825, porém, foi publicado um decreto que criava provisoriamente um curso jurídico com sede na Corte do Rio de Janeiro, com estatutos forjados pelo Visconde de Cachoeira e inspirados nos então vigentes na Universidade de Coimbra, frutos das reformas pombalinas dos estudos universitários ${ }^{4}$.

Conquanto houvesse um grande empenho para instalar tal curso, a decisão de onde seria definitivamente alojado só foi tomada em 5 de julho de 1826, quando na discussão da matéria pelo corpo legislativo prevaleceu a ideia de se criarem não um, mas dois cursos jurídicos: um ao Norte, na cidade de Olinda, e outro ao Sul, em São Paulo (BEVILÁQUA, 2012). Finalmente em 1827, após votação e aprovação da proposta pela Assembleia Geral, o Imperador D. Pedro I sancionou em 11 de agosto a lei que criou "os dois cursos de ciências jurídicas e sociais, um na cidade de $\mathrm{S}$. Paulo e outro na de Olinda" (BRASIL, 1827).

Ambas as faculdades são até hoje reconhecidas não apenas pelas contribuições ao direito nacional nos seus mais de 190 anos de existência, mas também por constituírem-se verdadeiros símbolos culturais da história do Brasil. A Faculdade de Direito do Recife (FDR) - na origem

\footnotetext{
${ }^{4}$ Para uma apreciação panorâmica destes estatutos na História do Direito português, cf. Costa (2019, p. 409-416). É de se destacar, ainda, quanto a os reflexos das reformas pombalina s na universida de portuguesa, dentre outros trabalhos recentes, a coletânea de ensaios: Ara újo (2014).
} 
denominada Curso Jurídico de Olinda - é afamada pela tradição de formar não apenas juristas ilustres, mas também por apresentar-se como celeiro de personalidades de destaque na história do Brasil independente. Diante de tantas figuras notáveis dela egressas, marcadamente do sexo masculino $^{5}$, pode-se questionar quais seriam as primeiras mulheres a despontar na história da instituição.

Ao realizar-se um salto reflexivo até os dias atuais, tem-se que as mulheres representam uma parcela expressiva dentre os discentes do ensino superior brasileiro. Conforme levantamento de dados do Censo da Educação Superior do Instituto Nacional de Pesquisas Educacionais Anísio Teixeira realizado em 2018, elas predominam no número total dos inscritos no ensino superior, tanto na modalidade de ensino presencial quanto à distância (INSTITUTO NACIONAL DE ESTUDOS E PESQUISAS EDUCACIONAIS ANÍSIO TEIXEIRA, 2019).

Na FDR (hoje unidade acadêmica da Universidade Federal de Pernambuco) ${ }^{6}$, também se observa uma ligeira preponderância feminina na composição do corpo discente de graduação. Ao averiguar os dados concedidos pela própria instituição, apurou-se que de um total de 1.240 discentes matriculados no primeiro semestre do ano de 2020, 686 alunos corresponde à parcela de mulheres, enquanto que 554 deste número representa o grupo de estudantes do sexo masculino (Universidade Federal de Pernambuco [UFPE], 2020a). Assim, tem-se que mais de 55\% (cinquenta e cinco por cento) dos discentes matriculados em 2020 no curso de Direito da UFPE é composto por mulheres. Tal predominância, todavia, não se observa no corpo docente da instituição, que no ano de 2019 de seus 68 docentes efetivos em exercício pouco mais de $35 \%$ (trinta e cinco por cento) correspondia a mulheres (UFPE, 2020b).

No passado, contudo, tal cenário diferia tanto no correspondente ao corpo discente quanto ao docente, reflexo da secular restrição da participação feminina na esfera pública, inclusive no âmbito da educação superior. Particularmente à presença feminina na docência na FDR, esta deuse apenas a partir da segunda metade do século XX, com Bernadette Neves Pedrosa, primeira professora admitida na instituição, com expressiva trajetória de ensino, conferências e publicações ${ }^{7}$. Também é digna de recordação a Professora Vera Regina de Cravo Barros Della Santa que foi a primeira mulher a assumir a coordenação do curso de Direito da UFPE, na gestão do Professor Sylvio Loreto, e também foi a primeira vice-diretora quando da Direção do Professor José Luiz Delgado (DELGADO, 2016). Além delas, destaca-se a gestão das professoras Luciana Melo e Fabíola Albuquerque, as quais estiveram como como Diretora e Vice-Diretora, respectivamente, por dois mandatos consecutivos efetivos (de 2007 a 2014) ${ }^{8}$.

\footnotetext{
${ }^{5}$ Cite-se, por exemplo, dentre as notá veis personalidades egressas da FDR, no âmbito das ciências jurídicas, Francisco de Paula Baptista (bacharelou-se em 1833), Clóvis Beviláqua (bacharelou-se em 1882) e Pontes de Miranda (bacharelou-se em 1919); no campo da política, Eusébio de Queirós (bacharelou-se em 1832), Joaquim Nabuco (bacharelou-se em 1870) e Epitácio Pessoa (bacharelou-se em 1886); e, no campo das artes, Raul Pompéia (bacharelou-se em 1885), Graça Aranha (bacharelou-se em 1886)e Augusto dos Anjos (bacharelou-se em 1907).

${ }^{6}$ Em 1946, a FDR foi reunida a outras escolas de ensino superior pernambucanas para a criação da Universidade do Recife, cujo primeiro reitor, Prof. Joaquim Amazonas, era o diretor. Em 1965, a Universidade do Recife passou a ser denominada Universidade Federal de Pernambuco (UFPE). Com a criação dos centros acadêmicos na UFPE, a FDR passou a denominar-se a dministrativa mente Centro de Ciências Jurídica s, porém, por respeito à sua tra dição e história, conseguiu manter em uso o nome anterior pelo qual a té hoje é conhecida.

${ }^{7}$ Formada em filosofia, Bernadette Pedrosa começou a lecionar na Faculdade de Direito do Recife de forma voluntária e gratuita durante o biênio 1963-1964, sendo admitida efetivamente na instituição em $1^{\circ}$ de janeiro de 1965 . Além de exercer função de docente da FDR, ta mbém era membra da Aca demia Perna mbucana de Letras Jurídicas (APLJ), onde ocupava a cadeira de número 29 (UFPE, 2020c). Durante sua trajetória, recebeu diversos títulos, dentre eles, o de cidadã do Estado de Pernambuco pela Assembleia Legislativa do Estado de Pernambuco em maio de 1998 (Perna mbuco, 1998), e o de Professora Emérita da Universidade Federal de Pernambuco, em novembro de 2006 (Aos, 2013). Em 2018 recebeu, ainda, uma homenagem a tra vés da produção de um documentário pela TV Justiça, o qual conta a sua trajetória e principais conquista (TEMPO, 2018). Dentre sua sublicações, destacam-se: "O fa to e a norma no direito internacional público", 1975; "A criação judicial do direito" (com Lourival Vilanova), 1978; Estado de direito e segurança nacional, 1978; e "Legitimidade democrática e equilíbrio de poderes", 1984.

${ }^{8}$ Nos mandatos da Prof. ${ }^{a}$ Diretora Luciana Grassano e da Prof. ${ }^{a}$ Vice-Diretora Fabíola Lobo, destacou-se a realização
} 


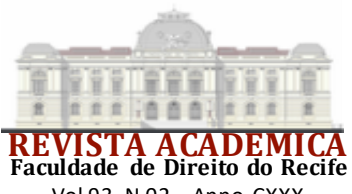

Vol.93 N.02 - Anno CXXX

Devido à importância de se lançar olhar sobre a educação enquanto contributo à emancipação e proteção à dignid ade das mulheres, este trabalho tem como objetivo geral promover um resgate histórico sobre a presença feminina no ensino superior brasileiro, em especial, na Faculdade de Direito do Recife, com destaque para a tentativa de recomposição das trajetórias estudantil e profissional de suas primeiras bacharelas.

A tarefa executada constitui-se, de certa forma e em grande medida, em um esforço que tem como referencial historiográfico o ensaio de Gláucio Veiga (1997) intitulado "A educação das mulheres: as primeiras bacharelas" - aqui constantemente citado, revisitado e, eventualmente, aperfeiçoado - com apoio em fontes colhidas de acervos arquivísticos, hemerográficos e bibliográficos. Executa-se uma revisão do trabalho historiográfico de Gláucio Veiga, com o cotejo do acervo disponível no Arquivo da Faculdade de Direito do Recife e, sobretudo, com jornais de época. Cuida-se, pois, de uma empresa de mirar mais além, sobre as costas de um gigante (nanos gigantum humeris incidentes).

O recurso aos periódicos gerais tem aqui uma importância central: são documentos (fontes) que narravam aspectos da vida social brasileira no século XIX e que frequentemente também se constituíam em repositórios de informações e debates de fundo jurídico. No caso das primeiras estudantes de direito do Brasil, o olhar para os jornais de época se mostrou importante pois este se constituiu em fato social bastante repercutido e acompanhado com atenção no ocaso dos Oitocentos. O material recolhido em tais periódicos, assim como em alguns outros de temática jurídica (como a Revista do Instituto da Ordem dos Advogados Brasileiros) contribuíram significativamente para evidenciar o que neste trabalho se pretende: a recomposição da teia de formação (e eventualmente de formação) jurídica feminina no Brasil, para além das fontes normativas, as quais - para dizer bem - eram interpretadas de modo a excluir a participação feminina no universo dos juristas.

O trabalho desenvolve-se a partir da aproximação a respeito da temática da admissão da mulher no ensino superior brasileiro - particularmente no ensino jurídico - e procura assimilar um paralelo entre tal inserção e algumas atuações do jurista Tobias Barreto de Menezes neste processo em Pernambuco no século XIX. Após isto, busca-se (re)conhecer as trajetórias estudantil e profissional das primeiras mulheres formadas na FDR e identificar possíveis contribuições suas no contexto social da época em que viveram.

\section{EDUCAÇÃO DA MULHER NA SOCIEDADE DO SÉCULO XIX}

Até o início do século XIX predominava em sociedade um ambiente familiar composto por relações aparentemente sólidas e bem definidas. Nesse contexto, à mulher era atribuíd o o papel de esposa dedicada ao lar, zelosa dos filhos e do marido com estímulos pelos meios médicos, educativos e da imprensa, para que a mulher assumisse um papel de guardiã do lar (D'INCAO, 2001).

Segund o Veiga (1997), o livro básico que até então tratava a respeito da educação feminina era L' Education des Filles, publicado em 1687 por François Fénelon, traduzido para o português em Pernambuco no ano de $1833^{9}$. De acordo com Fénelon, a mulher não deveria ser ignorante: sua instrução havia de vir por meio da moral e dos dogmas religiosos, o que a habilitaria a bem desempenhar seu papel na economia do lar. No entanto, ainda que Fénelon defendesse a instrução das mulheres, reputava necessário temer-lhe a sabedoria, uma vez que teriam elas o espírito mais

da reforma e restauro de vários a mbientes do palácio histórico da FDR o que possibilitou, por exemplo a reabertura do famoso Salão Nobre da Faculdade de Direito do Recife (SALÃO, 2011).

${ }^{9}$ Fénelon insere-se dentre os principais teóricos da chamada querelle desfemmes, um debate intelectual tra vado entre séculos XV e XVIII a respeito da natureza, capacida de e valor da mulher na moderna Europa. Para uma a preciação da obra de Fénelon em paralelo à de outro teórico da querelle des femmes, Jacques Du Bosc, remete-se ao trabalho de Fitzgerald (1999). 


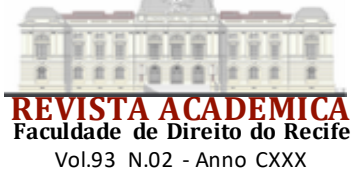

fraco e mais curioso que o dos homens e por isso não seria propício aplicá-las a estudos que as tornassem "caprichosas" (FÉNELON apud VEIGA, 1997, p. 281).

Por meio de fundamentos como este, sustentava-se à época que a mulher não poderia ocupar espaços públicos e não deveria "fazer parte do governo do Estado, nem da guerra, nem entrar no ministério das cousas sagradas" (FÉNELON apud VEIGA, 1997, p. 281). Por consequência, prescindível seria que elas adquirissem conhecimentos relacionados ao direito, à política, à filosofia ou à arte militar, sendo a educação feminina essencialmente destinada à leitura, à escrita, às regras elementares de aritmética, poesia, música, além da formação para habilidades indispensáveis para ser uma boa esposa e mãe (VEIGA, 1997; FREYRE, 2012).

Na sociedade brasileira dos Oitocentos, as mulheres de famílias com melhores condições financeiras geralmente tinham aulas em suas próprias casas com a presença de professores particulares ou então ingressavam em educandários religiosos, como internatos, nos quais era-lhes ensinada a "delicada arte de ser mulher" (FREYRE, 2012, p.110).

Contudo, em finais do século XIX assistiu-se a uma série de alterações advindas da modernização e da consolidação do sistema capitalista a implicar em câmbios estruturais da organização social. Nesse período, começaram a circular novas ideias que paulatinamente modificaram as formas tradicionais de conceber o mundo, com debates ideológicos a envolver, por exemplo, o liberalismo e o positivismo (LOURO, 2001). Emergiram, ainda, questões sobre a educação feminina, sendo a temática da emancipação das mulheres respaldada por vários teóricos como John Stuart Mill, em seu livro The Subjection of Women, de 1869.

Segundo Veiga (1997) o advento da revolução industrial também impulsionou a transformação da posição feminina na socied ade. A urbanização, a ascensão daburguesia aos altos postos do poder e, principalmente, a nova dinâmica produtiva capitalista são considerados os primeiros e principais fatores que modificaram drasticamente o papel social desempenhado pela mulher no século XIX.

Naquele momento, dentre as discussões em torno dessas mudanças sociais, era recorrente o debate sobre a relevância da educação na modernização do Brasil, principalmente quando se tratava da educação feminina (LOURO, 2001). Porém, com os debates surgidos na virada do século, emergiram grupos com ideias socialistas que, através de jornais libertários apontavam que a instrução da mulher seria uma arma privilegiada da libertação. Observa-se também a realização de encontros desses grupos e, inclusive, a promoção de palestras que tratavam da educação e participação da mulher no movimento operário e na sociedade (LOURO, 2001).

Em tal contexto surgiram novos ofícios que as mulheres poderiam assumir - além de seu papel de esposa e mãe -, sendo notadas as operárias que se fixaram nas fábricas, assim como mulheres de categorias sociais mais elevadas que conquistaram espaços de relativo destaque em variados ambientes sociais e que, pouco a pouco, assumiram outras ocupações além das do lar. Como exemplo, incumbiram-se dos ofícios de costureiras de atelier, professoras de colégio, e, principalmente, dedicaram-se à enfermagem e à medicina. Isso porque, as profissões voltadas à área da saúde pareciam "naturais" às mulheres por terem até àquele momento desempenhado as funções de "supervisoras da saúde doméstica e enfermeiras do lar" (GAY, 1988, p. 136). Esse pensamento também foi incorporado à sociedade brasileira, na qual se feminizou algumas ocupações, como a enfermagem e o magistério, pois, seriam profissões que teriam características femininas de sensibilidade e cuidado (LOURO, 2001).

\section{TOBIAS BARRETO E A DEFESA DA EDUCAÇÃO FEMININA}

No Brasil, um dos defensores da educação feminina foi o jurista Tobias Barreto de Menezes que no ano de 1879 tomou parte de discussões no parlamento provincial pernambucano a respeito do acesso das mulheres ao ensino superior na área médica.

Tobias Barreto de Menezes, jurista, filósofo, poeta e crítico brasileiro, nasceu na Vila de 
Campos do Rio Real ${ }^{10}$, Província de Sergipe, em 1839. Filho de Pedro Barreto de Menezes e de Emerenciana Maria de Menezes, devido às poucas condições econômicas de sua família, começou a trabalhar como professor de latim aos quinze anos de idade em Lagarto e Itabaiana (LIMA, 1939). Em 1862, aos 23 anos, chegou ao Recife com a intenção de continuar seus estudos e matricular-se na Faculdade de Direito do Recife. Contudo, por diversos motivos, seus planos foram adiados e o sergipano somente tomou parte da Faculd ade no ano de 1864 (VEIGA, 1997).

Durante o curso, desempenhou um relevante papel nos debates intelectuais, tendo colaborado em diversos jornais da época. Em 1869, bacharelou-se em Ciências Jurídicas e Sociais pela Faculdade de Direito de Recife. De 1871 a 1882 Tobias Barreto dedicou-se à advocacia e à política, vivendo na cidade pernambucana de Escada, onde foi eleito em 1878 deputado provincial por uma legislatura pelo Partido Liberal (LIMA, 1939).

Seguindo seu fascínio pelo magistério, prestou concurso para lente substituto da FDR em 1882 e, após aprovação, tomou posse do cargo em 14 de agosto do mesmo ano, destacando-se com contribuições nos campos da filosofia do direito e do direito penal. Em 7 de novembro de 1887, apenas dois anos antes de seu falecimento, ascendeu a professor catedrático (Arquivo daFaculd ade de Direito do Recife [AFDR], 1931), assumindo a primeira disciplina do quinto ano, Teoria e prática do processo (BEVILÁQUA, 2012).

Tobias Barreto é importante figura para a história da FDR e do Brasil, uma vez que além de sua destacada trajetória como jurista, porta consigo o papel de líder do movimento crítico, filosófico e jurídico, intitulado "Escola do Recife", que teve grande influência nas correntes do pensamento da época (LIMA, 1939). Além disso, o jurista sergipano também é recordado pelo envolvimento em discussões a respeito da educação feminina.

Em umas das partes do seu ensaio "A Alma da Mulher" - comentário ao livro Die Psyche des Weibes, de Adolf Jellinek - Barreto sustentou em benefício das mulheres "uma instrução profunda e seriamente ministrada" (BARRETO, 1883, p. 19), pois, no seu entender, seriam elas superiormente inteligentes aos homens devido à sua vivência e intuição. Tobias Barreto denunciava a concepção de inferiorid ade feminina em relação ao homem ao criticar a ideia de que a mulher limitar-se-ia apenas aos papéis de mãe de família. Nesse sentido, questionava ele: “[...] o desenvolvimento da essência feminina, no sentid o de concentrá-la e reduzi-la ao circuito único de família, tem sido natural e regular? [...]" (BARRETO, 1883, p. 17). Além disso, também julgava que as mulheres deviam ser estimuladas para que seus cérebros não atrofiassem, "[...] reduzindo a inércia funcional dos olhos das corujas, ou das asas da ema. [...]” (BARRETO, 1883, p. 19).

Antes de publicar este trabalho, porém, Tobias Barreto fomentara a reflexão a respeito da emancipação das mulheres quando da sua breve atuação no parlamento. Eleito deputado na Assembleia Provincial de Pernambuco em 1878, Tobias tomou parte dos debates a respeito da educação feminina quando da apreciação do Projeto de Lei n. 61/1879 e na propositura do Projeto de Lei n. 129/1879.

O Projeto de Lei n. 61/1879, de autoria do deputado Silvino Guilherme de Barros, o Barão de Nazaré, pretendia a concessão de ajuda mensal no valor de 100 mil réis para que a jovem pernambucana Josefa Agueda Felisbela de Oliveira estudasse medicina no exterior. A proposta repercutiu no parlamento pernambucano, tendo alguns deputados favoráveis apresentado emendas com o fim de estender a bolsa de estudos para outras discentes ${ }^{11}$. Dentre aqueles figurava Tobias Barreto que, além de defender a proposta opondo-se fortemente com argumentos científicos às opiniões contrárias dos deputados Malaquias da Rocha e Ermírio Coutinho, sustentou a extensão da ajuda financeira à Maria Amélia Florentina Cavalcanti de Albuquerque, uma ex-aluna sua:

\footnotetext{
${ }^{10}$ A Vila de Campos do Rio Real atualmente corresponde a o município de Tobias Barreto no Estado de Sergipe.

${ }^{11}$ Uma narrativa reconstitutiva da discussão no parlamento pernambucano em torno do referido projeto de lei, apresentado atendendo à instância do Romualdo Alves de Oliveira, pai de Josefa Felisberta de Oliveira, pode ser encontrada em Cavalcanti(1959,p. 150-154).
} 


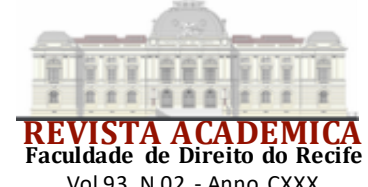

Vol.93 N.02 - Anno CXXX

\begin{abstract}
Votando, portanto, como desde já empenho o meu voto em favor do projeto, eu ouso adicionar-lhe uma emenda, em prol de um outro espírito esperançoso e prometedor, de quem tive, por algum tempo, a honra de ser mestre e mestre que muitas vezes teve de possuir-se de uns certos receios diante do talento de sua discípula. Refiro-me à Sra. D. Maria Amélia Florentina, filha do Sr. João Florentino Cavalcanti.

Esta moça estudiosa, aproveitando a ocasião que mais azada se lhe of erece, dirige assim, por meu intermédio, à representação de sua província um pedido que já há algum tempo projetara dirigir-lhe, para ver se consegue levar a efeito o seu mais íntimo desejo, que é o desejo de ilustrar o seu espírito, o desejo de instruir-se (BARRETO, 1977, p. 346).
\end{abstract}

Apesar de o Projeto n. 61/1879 ter sido aprovado pela Assembleia de Pernambuco, não obteve ele a sanção do Presidente da Província. Josefa Felisberta de Oliveira, porém, conseguiu estudar nos Estados Unidos, send o colega de curso de Maria Augusto Generoso Estrela, primeira mulher brasileira a se formar em medicina. Maria Amélia Florentina, por sua vez, laureou-se no Brasil, tornando-se a primeira médica pernambucana (CAVALCANTI, 1959; ARRUDA, 2016).

Também Tobias Barreto destacou-se na elaboração e defesa do Projeto de Lei n. 129/1879 no qual foi abordada a questão da educação pública, a criação de escolas e a orientação para o ensino universitário feminino. A proposta pleiteava a reforma da instrução pública a partir da criação de uma escola pública secundária específica para as mulheres. Segundo destacado pelo próprio Tobias:

Este projeto, que teve apenas o succés d'estime de passar em primeira discussão, continha a ideia da criação de um estabelecimento público de cultura literária e profissional para as moças, sob a denominação de Partenogógio do Recife, e dividido em duas escolas: escola média (Mittelschule), e escola superior (Honere Schule). Não preciso dizer que a minha idéia pareceu então um sonho de poeta (BARRETO, 1883, p. 24).

O trecho acima foi extraído de uma nota contida na terceira parte do ensaio "A alma da mulher", no qual Tobias Barreto recorda a propositura do projeto de lei e vale-se da expressão "Partenogógio do Recife" para se referir à escola projetada. O termo foi forjado como uma analogia ao Partenon de Atenas, edifício dedicado a Atenas, deusa da sabedoria (BARRETO, 1883).

Ciente das dificuldades na aprovação de uma proposta ousada como a sua, Tobias Barreto reconhecia que o seu "sonho de poeta" estava condenado à "morte prematura" (BARRETO, 1926, p. 91). De fato, a proposta foi lida na sessão de 28 de março de 1879 e posteriormente discutida em plenário na Assembleia Provincial de Pernambuco em duas sessões: a primeira no dia 2 de maio de 1879 e a segunda no dia 5 de março de 1880, oportunidade na qual Tobias Barreto já não era deputado, assumind o a sua defesa o Barão de Nazaré, também dela signatário. Ao final, porém, a proposta de criação do Partenogógio foi rejeitada.

A curta atuação parlamentar de Tobias Barreto em Pernambuco, embora não tenha implicado em mudanças sociais concretas, contribuiu para açular no ambiente da política provincial a reflexão sobre o tema da chamada questão da mulher, em especial no que tange à emancipação feminina através da educação e de sua inserção no ensino superior brasileiro.

Cônscio de que natura non facit saltus, Tobias Barreto, como destacou Veiga (1997, p. 286), "não desejava mudanças revolucionárias, violentas, nada vulcânico". Com efeito, ele referiase a si como "relativista: atendo muito às condições de tempo e de lugar" (BARRETO, 1977, p.338). O tema da emancipação da mulher, segundo a sua leitura relativista, deveria ser visualizado sob três ângulos distintos: o político, o civil e o social. E naquele momento Barreto sustentava apenas uma emancipação social, que compreendia "a emancipação científica e literária da mulher, emancipação que consiste em abrir ao seu espírito os mesmos caminhos que abrem os espíritos 


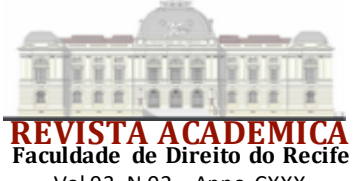

Vol.93 N.02 - Anno CXXX

dos homens" (BARRETO, 1977, p. 339).

A respeito de tal posição restritiva de Tobias Barreto, que ao tempo em que reconhece a amplitude das formas de emancipação feminina restringe a sua apologia apenas a um campo (o social), Gláucio Veiga sustenta que Tobias Barreto "jamais enfrenta a estrutura estamental nas raízes. Aponta erros, de logo; soluções ao longe” (VEIGA, 1997, p. 287). Apesar disso, é inegável que a atuação parlamentar de Tobias Barreto no que concerne aos mencionados projetos de lei é digna de rememoração, uma vez que naquele momento muito representou para a defesa da educação feminina e, notadamente, para inserção das mulheres no ensino superior brasileiro e em especial em Pernambuco.

\section{PRESENÇA FEMININA DO ENSINO SUPERIOR BRASILEIRO: MEDICINA E DIREITO}

A partir de intercessões como as de Tobias Barreto deu-se o paulatino progresso rumo à concretização da entrada das mulheres no ensino superior brasileiro ${ }^{12}$. Seguindo uma tendência mundial notad a no século XIX de inicialmente acolher as mulheres como estudantes em cursos de saúde, o Brasil teve suas primeiras mulheres discentes do ensino superior nos cursos de medicina.

A primeira mulher do Brasil - e da América do Sul - a graduar-se em um curso superior foi a carioca Maria Augusta Generoso Estrela, estudante de medicina que se formou nos Estados Unidos no ano de 1882 (TRINDADE; TRINDADE, 2011). Foi apenas em 1887, porém, que ocorreu a graduação de uma mulher brasileira em uma faculdade nacional (BELTR ̃̃O; ALVES, 2009), uma vez que as mulheres não tinham o direito de frequentar as faculdades no Brasil até o advento do Decreto $\mathrm{n}^{\circ}$ 7.247, de 19 de abril de 1879 (BRASIL, 1879), que operou a "Reforma do Ensino Primário e Secundário do Município da Corte e o Superior em todo o Império".

Tal reestruturação legislativa, chamada de "Reforma do Ensino Livre", de autoria de Carlos Leôncio de Carvalho, além de instituir "completamente livre" o ensino primário e secundário no município da Corte e o superior em todo o Império, ao tratar das Faculdades de Medicina em seu artigo 24, § 20, facultou expressamente a inscrição de "indivíduos do sexo feminino" no "curso geral", na "Escola de pharmacia", no "curso obstetrico" e no "curso de cirurgião dentista" (BRASIL, 1879). Dessa maneira, a reforma de 1879 possibilitou o acesso das mulheres ao ensino superior no país, matriculando-se a partir do ano de 1881 as primeiras alunas (LOBO, 1971) ${ }^{13}$.

Após a concessão da matrícula de mulheres no curso de medicina no Brasil houve sucessivamente o ingresso feminino também em cursos de outras áreas do conhecimento, dentre as quais, o direito.

As primeiras bacharelas em direito do Brasil foram as pernambucanas Delmira Secundina da Costa, Maria Coelho da Silva Sobrinha e Maria Fragoso Orlando da Silva, as quais concluíram o curso em 1888: as duas últimas obtiveram o grau em 6 de novembro de 1888; a primeira, uma semana depois, em 17 de novembro.

\footnotetext{
12 Registre-se, porém, que desde a Idade Média (e mesmo em tempos mais remotos) há registros de grandes contribuições femininas ao conhecimento intelectual ocidental, como recentemente destacado na obra de Costa \& Costa (2019). Na área jurídica, vale recordar que a primeira estudante do sexo feminino da Alma Mater Studiorum (Universidade de Bolonha) teria sido Bettisia Gozzadini no séc. XIII, sendo também, mui provavelmente, a primeira mulher professora de direito (Eco, s.d.). No campo das ciências médicas a figura de Dorotea Bucca é recordada por ter leciona do medicina ta mbém em Bolonha no séc. XIV.

${ }^{13}$ Dentre as pioneiras no curso médico tem-se Rita Lobato que se inscreveu na Faculdade de Medicina do Rio de Janeiro em 1884 e que depois transferiu-se para a Faculdade de Medicina da Bahia onde concluiu o curso, com distinção, em dezembro de 1887 , tornando-se a primeira mulher brasileira a graduar-se em uma faculdade nacional (SCHUMAHER; BRAZIL, 2000; RAGO, 2015).
} 
Figura 1 - Primeiras bacharelas da FDR na capa do "Recife Illustrado" de 13 de novembro de 1888.

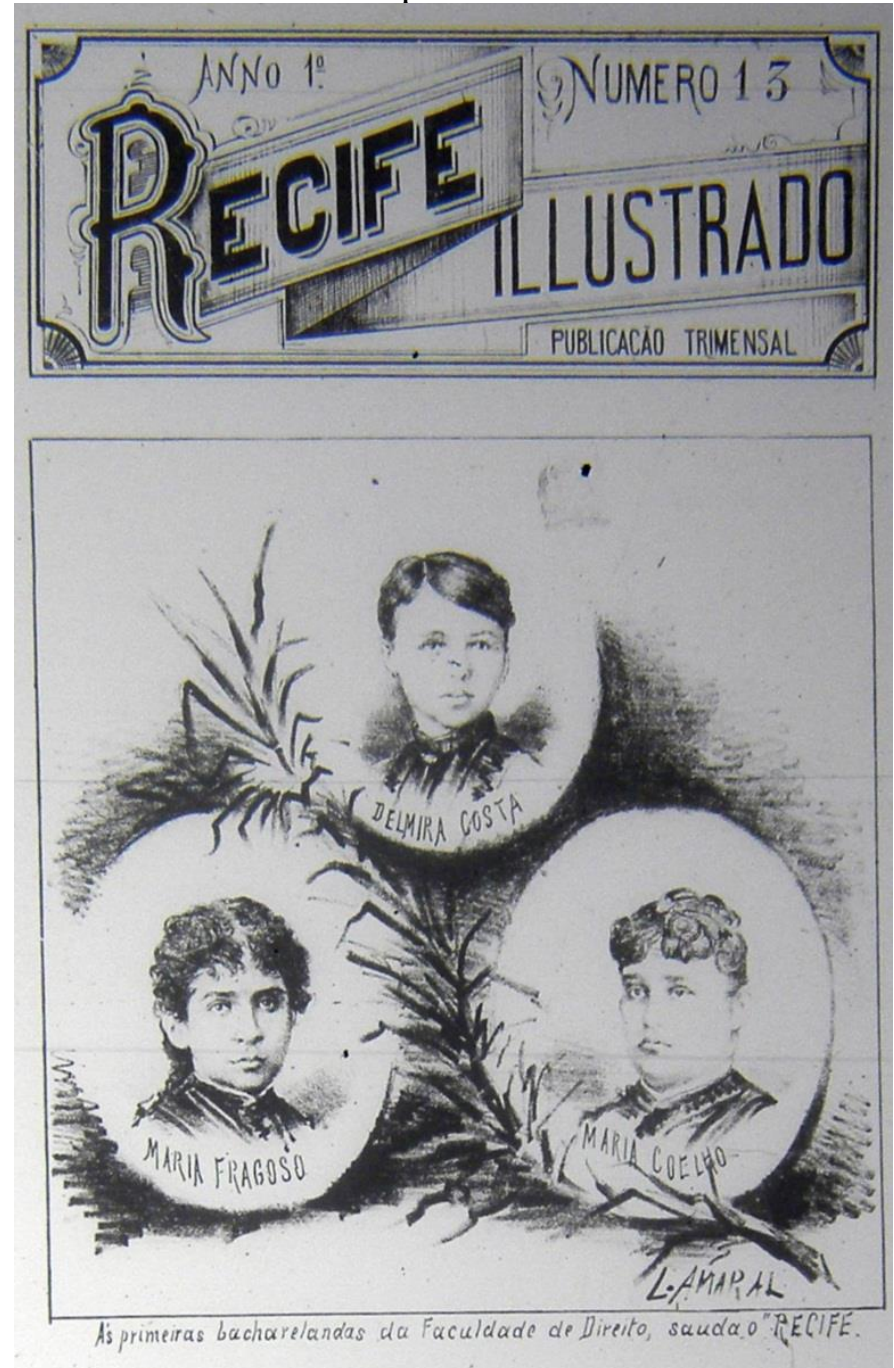

Fonte: Fundação Joaquim Nabuco (FUNDAJ). Coordenação-Geral de Estudos da História Brasileira (CEHIBRA). Microfilmagem. Recife Illustrado, ano 1, n. 13, 1888.

A formatura das primeiras egressas da FDR foi um evento muito comentado nos principais jornais da época, constituindo-se "um ato acadêmico que acabou se transformando em fato acadêmico e logo depois em fato histórico" (VEIGA, 1997, p. 294). Com efeito, como observou Beviláqua (2012, p. 286) o fato "atraiu grande concorrência à solenidade, não somente por ser caso novo, como, ainda, porque significava grave mudança na mentalidade brasileira no sentido do progresso".

Na edição do Diário de Pernambuco de 7 de novembro de 1888, após frisar as duas mulheres dentre os que compunham a lista dos aprovados no exame oral do $5^{\circ}$ ano, dizia-se serem aquelas "senhoras as primeiras que no Brasil se formam em direito, o que demonstra que novos horizontes podem ser conquistados pela intelligência da mulher" (DIARIO DE PERNAMBUCO, 1888a, p.2). E, ainda, a edição de 5 de dezembro de 1888 do jornal maranhense O Paiz registrava: "cremos que são as primeiras senhoras que n'este paiz, recebem o título de bacharéis em direito" (O PAIZ, 1888, p.2).

O periódico Recife Illustrado dedicou a capa da edição de seu número 13 de novembro de 1888 a uma ilustração das pernambucanas pioneiras bacharelas em direito do Brasil (Figura 1). Em artigo publicado na mesma edição da revista intitulado "Hymnos e palmas", aquela formatura foi lembrada como um acontecimento de extrema importância para a história literária de 
Pernambuco proporcionado pelas "que calcando os futeis preconceitos demonstraram brilhantemente que a Mulher pode e deve tomar parte no festim das Lettras" (PIPERLIN, 1888, p.2). A formatura de Delmira Secundina Costa, realizada no dia 17 de novembro de 1888, foi igualmente muito festejada (DIARIO DE PERNAMBUCO, 1888b).

Em 1889 foi a vez da conclusão do curso por Maria Augusta Coelho Meira de Vasconcelos, que passou a integrar o grupo das pioneiras bacharelas em direito do Brasil, ainda no século XIX pela FDR, na qual também se formou a alagoana Anna Alves Vieira Sampaio Duarte em 14 de dezembro de 1893 (AFDR, 1881-1894, p.198v).

A nível nacional, soma-se a estas Myrthes Gomes de Campos, formada em 1899 pela Faculdade Livre de Ciências Jurídicas e Sociais e que se destacou em sua vida profissional devotada à profissão jurídica, reconhecida e festejada como a primeira mulher advogada do Brasil. As primeiras bacharelas pernambucanas, contudo, não alcançaram projeção e fama semelhantes à de Myrthes de Campos. Apesar disso, dad o o seu pioneirismo acadêmico em um tempo e sociedade tão particularmente adversos ao progresso das mulheres no campo do trabalho merecem ser recordadas suas trajetórias acadêmica e profissional, caminho este que pode ser considerado de algum modo preparado em Pernambuco por Tobias Barreto, que era lente da FDR ao tempo em que elas ali estudaram ${ }^{14}$.

\section{AS PRIMEIRAS BACHARELAS EM DIREITO DO BRASIL}

No intuito de promover um resgate histórico sobre a presença feminina no ensino superior brasileiro e, em especial, na Faculdade de Direito do Recife, será realizada uma recomposição da trajetória estudantil e profissional de suas primeiras bacharelas. Pretende o esboço doravante construído - sem intuito puramente biográfico - congregar as informações colhidas nos materiais bibliográficos, arquivísticos e hemerográficos utilizados.

\subsection{DELMIRA SECUNDINADA COSTA}

A pernambucana Delmira Secundina da Costa nasceu em 27 de agosto de 1866 (AFDR, 1884). Em 8 de março de 1884, aos 18 anos de idade, matriculou-se na Faculdade de Direito de Recife, tornando-se a primeira mulher a ingressar no curso de direito em todo o Brasil (AFDR, 1866-1889).

Segund o o artigo publicado pelo Diario de Pernambuco em 1 de março de 1884, à Delmira Secundina e à estudante de medicina Maria Amelia Cavalcanti havia de ser dado todo o reconhecimento por terem ambas completado o curso de humanidades com as melhores notas e também pela importância de sua inserção no ensino superior: "rompendo todos os obstáculos que se lhes apresentavam no caminho, chegaram gloriosamente ao seu termo, tendo ambas sempre obtido os melhores grãos de aprovação" (DIARIO DE PERNAMBUCO, 1884, p. 4).

Durante o curso jurídico, Delmira Secundina foi uma estudante modelar. Seu desempenho acadêmico foi noticiado em jornais de tod o o Brasil, como quando lhe foram lançados elogios por ocasião da sua aprovação plena na primeira prova oral do primeiro ano (DIARIO DO BRAZIL, 1884, p.2) e quando em 1887, após aprovação nas matérias do terceiro ano, foi louvada como alguém "cuja inteligência tem sempre se revelado brilhantemente" (A PROVINCIA do Espíritosanto, 1887, p. 2), sendo também lembrada como "futura doutora" pelo periódico maranhense Pacotilha (1887, p. 3).

${ }^{14}$ É digno de registro o apreço que possuíam as primeiras bacharelas da FDR a Tobias Barreto, falecido no ano de 1888, exatamente o mesmo no qual as três primeiras estudantes se formaram. Em 1889, o Jornal do Povo, de Pernambuco, noticiava a ativa e profícua a tuação das já doutoras Maria Coelho, Delmira Costa e Maria Fragoso na comissão de senhoras do bando precatório em favor da família de Tobias Barreto, que falecera em estado de penúria (PATRIMONIO, 1889). 


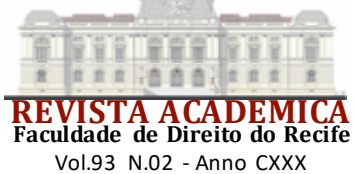

Delmira Secundina formou-se em 17 de novembro de 1888, após Maria Fragoso Orlando da Silva e Maria Coelho da Silva Sobrinha, discentes que iniciaram seus estudos na instituição em 1885 (AFDR, 1931, p. 51). Quando lhe foi conferid o o título de bacharela, Delmira foi saudada com uma prolongada salva de palmas e foi coberta de flores. Foi também, conduzida pelo braço do político e abolicionista pernambucano José Mariano, sendo acompanhada até a sua residência, juntamente com lentes e colegas do curso acadêmico (A REGENERAÇÃ̃, 1888, p. 1), a revelar o reconhecimento público de sua conquista no Recife.

No entanto, apesar da notoried ade derivada de seu insólito pioneirismo durante a graduação - observada pelas referências ao seu nome em periódicos contemporâneos - não são encontrad os registros quanto à atuação profissional de Delmira Secundina da Costa. A tal respeito, observa Veiga (1997) que Clóvis Beviláqua ao tratar da formatura de Delmira Secundina não a exalta tanto pelo seu pioneirismo e feitos pessoais, mas pelas suas relações com importantes homens, como por ter casado com Gabriel Henrique de Araújo em 1896 (JORNAL DO RECIFE, 1896, p. 3), ou por ser irmã de Alfredo Costa. Ainda, segundo Veiga (1997, p. 294), "a dra. Delmira Secundina da Costa diluiu-se nas atividades do lar, e ao que parece, melhor dotada em prendas ditas domésticas". Com efeito, a figura de Delmira Secundina, dentre as três pioneiras retratadas na edição do Recife Illustrado, conquanto tenha sido a primeira estudante de direito do Brasil, é pouco lembrada após a sua formatura, pelo que se pôde notar nas fontes consultadas, sem menções à atuação sua nos campos profissional ou literário, como ocorre em relação às demais precursoras da FDR ${ }^{15}$.

\subsection{MARIA COELHO DA SILVA SOBRINHA}

A pernambucana Maria Coelho da Silva Sobrinha matriculou-se em 21 de março de 1885 na FDR onde, como já referido, integrou na turma dos bacharéis de 1888.

No artigo intitulado "O progresso do bello sexo", publicado no Diario de Pernambuco, em 15 de novembro de 1888, registrava-se que Maria Coelho colara grau no dia 6 de novembro anterior, sendo o fato motivo de alegria por ser aquela "do Brasil a primeira sobre cuja a cabeça pousou pela primeira vez o distinctivo dos bachareis" o qual "até então só tinha sido conferido ao sexo forte" (DIARIO DE PERNAMBUCO, 1888c, p.3). A comemoração da sua formatura deu-se com uma grande festa realizada em sua casa da qual tomou parte a sociedade recifense que, ao som de duas bandas de música, celebraram o feito (DIARIO DE PERNAMBUCO, 1888c, p.3).

Após o término do curso jurídico, Maria Coelho dedicou-se por algum tempo à advocacia criminal, tendo subido à tribuna do júri no Rio de Janeiro em 10 de outubro de 1899, poucos dias depois de Myrthes Gomes de Campos, que nele estreara em 22 de setembro daquele ano (AZEVEDO, 1903). Nesse sentido, resta imprecisa a afirmação feita por Gláucio Veiga quanto ao fato de ter sido Maria Coelho "a primeira mulher a subir na tribuna do júri no Brasil" (VEIGA, 1997, p. 293). Na verdade, em mais de um periódico consultado registra-se a informação de que Maria Coelho da Silva Sobrinha tentara atuar no júri dez anos antes. Em 1889, pouco depois de formada no Recife, seu intento foi frustrado por ser-lhe negada a palavra pelo juiz diante da alegação de que no tribunal não poderiam ser admitidas "inovações" (DRA., 1889, p.1). Também a revista A Mensageira, focada em temas femininos, registrou quanto ao debute de Maria Coelho que ela:

[...] principiou o seu discurso dizendo que duas vezes lhe tinham recusado a

${ }^{15}$ Neste particular, destaque-se que um leitor cujo nome não foi divulgado, procurou restaurara memória de Delmira Secundina da Costa ao veicular em jornais no ano de 1900 que, para além do reconhecimento de Maria Coelho da Silva Sobrinha como primeira bacharela, havia -se de ter em conta que a ela "cabe a gloria de ter sido a primeira que, rompendo com os preconceitos, se matriculara na Escola de Direito de Pernambuco em 1884" (JORNAL PEQUENO, 1900,p. 2; A PROVINCIA, 1900,p. 1). 


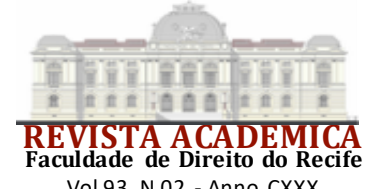

Vol.93 N.02 - Anno CXXX

palavra no jury, no Recife. Em seguida defendeu os direitos da mulher, passando a analysar o processo. Houve replica e treplica, tendo se sahido brilhantemente a defensora, que foi muito felicitada. (A MULHER no tribunal, 1899, p. 184).

Maria Coelho apresentou-se ao júri sob a presidência do juiz Viveiros de Castro portando o livro Philocrítica de Artur Orlando na presença de várias mulheres no recinto do tribunal, dentre as quais Myrthes de Campos ${ }^{16}$ (NO JURY, 1899, p.1). Maria Coelho obteve a absolvição do réu acusado de roubo, feito este que rendeu vários cumprimentos e destaque na imprensa da época (AZEVEDO, 1903, p. 219; A MULHER, 1899, p. 184; DRA., 1889, p.1).

No entanto, diversamente daquela que seria consagrada como a primeira advogada brasileira, Maria Coelho não se consolidou na carreira jurídica, voltando-se aos ofícios docentes como era comum às mulheres de seu tempo ${ }^{17}$. Fundara em 1895 , em sua própria residência, um colégio particular voltado para o ensino primário e secundário de meninas. Nesta escola eram ministradas aulas de português, francês, inglês, aritmética, trabalho de agulhas, piano e música (DIARIO DE PERNAMBUCO, 1895, p.3). Posteriormente, a escola recebeu a denominação de "Instituto 19 de Março" tend o a bacharela Maria Coelho da Silva Sobrinha assumido o cargo de sua diretora (DIARIO DE PERNAMBUCO, 1898, p. 2).

\subsection{MARIA FRAGOSO}

Filha de Izabel Maria Fragoso e João Baptista Fragoso a pernambucana Maria Fragoso nasceu em 1866. Seu pai era um tradicional e abastado comerciante da cidade do Recife, tendo sua família boas condições financeiras. Devido ao insucesso da sociedade Amorim, Fragoso, Santa \& Cia, seu pai teve que se desfazer de seus bens, reduzindo-se à situação de pobreza. Tal episódio traumático teria sido, segundo Veiga, um dos fatores que motivou Maria Fragoso a escolher a profissão de advogada, imbuída "na esperança de redimir o nome do pai e de reaver o seu patrimônio" (VEIGA, 1997, p. 295-296).

Após a realização dos exames do Colégio das Artes, Maria Fragoso ingressou na Faculdade de Direito do Recife onde se submeteu aos exames do $1^{\circ}$ ano do curso em 1885. Maria Fragoso obteve o grau na FDR em 7 de novembro de 1888 e destacou-se no campo das reivindicações femininas. Sempre presente em círculos intelectuais recifenses em companhia do seu esposo Artur Orlando, discípulo de Tobias Barreto, e também de outras mulheres. Publicou em 1904 o ensaio "A Questão da Mulher" na Revista "Cultura Acadêmica", um dos veículos de divulgação de ideias da chamada "fase tardia" da Escola do Recife, na qual sustentou ideias emancipacionistas femininas.

Para Maria Fragoso (1904), a questão da mulher era falsamente colocada quando se defendia a inferioridade em relação ao homem ou se postulava a igualdade dos sexos. Em sua concepção, não se pode afirmar que o sexo feminino seja superior ao masculino tampouco que lhe seja igual, “[...] porque não se podem comparar senão valores semelhantes, os dois são diferentes por sua própria natureza, quer dizer, as differenças são inherentes à sua própria organização" (FRAGOSO, 1904, p. 233). Maria Fragoso sustentava que devido às diferenças entre homem e mulher cada um teria uma função específica e uma organização adaptada às suas missões, o que

\footnotetext{
${ }^{16}$ Anos depois, em uma entrevista concedida a o Diário de Notícias do Rio de Janeiro, disse Myrthes de Campos que as atuações sua e de Maria Coelho no tribunal do júri deram -se graças a o beneplácito do juiz Francisco José Viveiros de Castro que "foi o primeiro a arrostar os preconceitos em voga, permittindo-me defender um acusado perante o Tribunal do Jury, sob a sua esclarecida presidencia, fazendo depois, identica permissão á dra. Maria Coelho da Silva, que já havia muitos annos era diplomada pela Faculdade de Direito do Recife, sem ter inicia do a advocacia" (Formada em direito, 1940, p. 3).

${ }^{17}$ Isto não excluiu, porém, o potencialexercício da atividade jurídica por Maria Coelho da Silva Sobrinha, tanto que se registra em 1904 a informação no Jornal Pequeno (1904, p.2) de que ela oferecera seus serviços advocatícios ao deputado Alfredo Varella, o qualos recusara e, delicadamente, a gradecera a proposta.
} 
reforçaria a natureza indispensável de reciprocidade necessária de ambos os sexos. Defendia ela, ainda, o trabalho externo das mulheres, seja como suporte às necessidades da economia doméstica, seja em seu proveito próprio:

\begin{abstract}
Nas famílias modestas, em que o chefe não conta senão com os recursos de seu trabalho, o descontentamento do homem pela concurrencia da mulher toca ás raias do contrasenso. Neste caso é que o trabalho justamente se impõe a mulher, não só para auxiliar as despezas da familia mas ainda para satisfazer os gosos de arte, dos quaes ella tem necessidade. Aquelles que entendem que a emancipação da mulher importará o captiveiro do homem, pertencem áquella categoria de espíritos, que não veem em a natureza outra coisa senão contrastes, importando a affirmação de um termo a negação do outro, como finito e infinito, par eimpar, uno e mutiplo, direito e esquerdo, recto e curvo, masculino e feminino, e assim por deante (FRAGOSO, 1904, p. 239).
\end{abstract}

Nas fontes consultadas não foram encontrados registros da atuação de Maria Fragoso nos misteres da prática jurídica ao longo de sua vida. Faleceu em 1947, aos 81 anos de idade (DIARIO DE PERNAMBUCO, 1947; RECIFE [PE], 1947).

\title{
5.4 MARIA AUGUSTA COELHO MEIRA DE VASCONCELOS
}

Nascida em 9 de maio de 1872, também na Província de Pernambuco, filha de Joaquina Coelho Meira de Vasconcelos e do Capitão Ascêncio Minervino Meira de Vasconcelos (SCHUMAHER; BRAZIL, 2000), Maria Augusta Coelho Meira de Vasconcelos ingressou no ano de 1885 na FDR onde bacharelou-se, com distinção, em Ciências Jurídicas e Sociais em 19 de novembro de 1889, constituindo-se na "quarta representante do sexo fragil que recebe em nossas Faculdades Jurid icas a honrosa laurea de Ulpiano" (JORNAL DO RECIFE, 1889, p. 1).

As pesquisas realizadas nos acervos consultados não nos permitem, porém, afirmar que Maria Augusta Coelho Meira de Vasconcelos seguiu nas funções de bacharel em direito. Nesse sentido, é necessário registrar que carece de fontes a afirmação feita por Luzilá Ferreira (2002) quanto à suposta tentativa de inscrição de Maria Augusta Coelho Meira no Instituto da Ordem dos Advogados do Brasil (IOAB) ${ }^{18}$. Além da mencionada deficiência de fontes, o cotejo dos dados por vagamente apresentados por Ferreira (2002) com outros documentos relativos à advocacia feminina no Brasil levam-nos a hipotetizar ter havido de sua parte certa confusão com a outra "Maria Coelho" (da Silva Sobrinho) ou mesmo com o caso de Myrthes de Campos, ambas envolvidas nas discussões sobre a mulher ad vogad a no IOAB, logo após suas atuações no Tribunal do Júri no Rio de Janeiro.

Com efeito, os documentos concernentes ao pedido de inscrição de Myrthes de Campos como membro doIOAB em 1899 e o parecer do subprocurad or federalque funcionou no processo em que atuou Maria Coelho da Silva Sobrinho - ambos publicados na Revista O Direito, em 1900 - não apresentam registros quanto a eventuais instâncias de Maria Augusta Meira nesse sentido (A MULHER-ADVOGADO, 1900). Os dados colhidos, porém, revelam-na em seu primeiro ano de bacharela como uma mulher ativa, não apenas envolvida nos afazeres familiares, mas também na luta em favor dos direitos da mulher e contra a misoginia de seu tempo.

Logo após sua formatura encontramos o seu nome elencado dentre os integrantes da direção

$18 \mathrm{O}$ trecho da afirmação feita pela autora é este: "Maria Augusta não se limita a escrever aos jornais. Dirige-se ao diretor da Instrução Pública, escreve ao governador provisório do Brasil, e mesmo ao mare chalDeodoro da Fonseca, instância máxima do País, no intento de saber 'qua is as funções que, como bacharel' podia exercer. (...) O documento chegou até a instituição que seria hoje a Ordem dos Advogados, e depois de muitas discussões, a resposta definitiva ao problema lhe vem: o Direito brasileiro inspira-se no Direito Romano. Ora, em Roma mulheres não exerciam a magistratura. Logo..." (Ferreira 2002,p.20). 


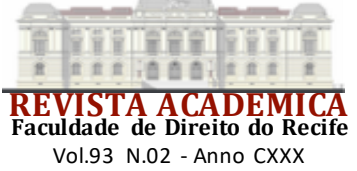

do Colégio Meira, pertencente à sua família e que, segundo anúncios publicados em jornais pernambucanos em 1890, estava apto a preparar futuros alunos para entrada na FDR, assegurandose o funcionamento do curso primário pelas filhas do diretor, dentre as quais Maria Augusta Meira (DIARIO DE PERNAMBUCO, 1890). Ela, porém, não parecia satisfeita e cômoda em apenas seguir o ofício de educadora, atribuição tradicionalmente associável à imagem do feminino, como usado nas propagandas do Colégio Meira. Conquanto não se possa afirmar ter enveredado no exercício das funções jurídicas, Maria Augusta Meira envolveu-se em 1890 na causa emancipacionista feminina, mais especificamente na vertente do sufragismo.

Após consulta feita à comissão distrital de Itabapoana sobre o direito das senhoras ao voto, obteve uma resposta negativa no sentido de que tal ideia não havia sido cogitada, obstando-se o direito ao alistamento eleitoral feminino. Irresignada com a notícia da negativa chancelada por Cesário Alvim, Ministro do Interior, Maria Augusta Meira fez publicar no "Jornal do Recife" em abril de 1890 um artigo intitulado "Uma decisão injusta", no qual se expressou com altivez contra a posição ministerial e, ao cabo, questionou a própria razão de ser da permissão de acesso das mulheres aos cursos superiores se, ao final, o título obtido sequer valeria como prova de "instrução", uma das condições exigidas à época para a aquisição do direito de voto. Dizia Meira de Vasconcelos quanto à decisão do Ministro do Interior:

A decisão desarrasoada de 21 de Março que é uma prova irrecusável de que S.Exc. é solidário como governodecahido, na cilada que armou ás mulheres, permitindo que ellas cursassem as Faculdades somente para ter o direito aos impostos cobrados pela matricula, longe de me desanimar e de me fazer recuar da tarefa que me impuz, é um incentivo para continuar na propaganda em favor da emancipação da mulher (VASCONCELLOS, 1890a, p.2).

O texto-manifesto destinava-se, ainda, a chamar a atenção das mulheres, potenciais eleitoras de Maria Augusta Meira no pleito eleitoral que se avizinhava:

A vós todas, Senhoras, que contribuis com os impostos para o Estado, á vós professoras publicas tituladas, á vós empregadas públicas e quantas pernambucanas ilustres e brasileiras em geral, ergo o brado da animação para que com a maxima perseverança e renhida pertinácia me ajudeis na construcção deste grande monumento para fazer florescer o direito que nos assiste [...] Assim, pois, Senhoras, por ventura vós reconhecendo este aviltamento que se nos destina, vos negareis a collaborar commigo em tão espinhosa tarefa? (VASCONCELLOS, 1890a, p.2).

Como forma de resposta ao artigo de Maria Augusta, o jornal "A Lanceta" publicou matéria intitulada "Um conselho", por meio da qual "recomendava" que a jovem desistisse do direito ao voto:

Por pensarmos assim, sinceramente, tomamos a liberdade de sahir do encontro da illustre doutora que hontem publicou um artigo do Jornal do Recife, para dizerlhe que eleitores ja temos em grande numero, que o que nos falta é a dedicação das mulheres para utilidade do lar e não para doutoras com direito de comparecer nos comicios (UM CONSELHO, 1890, p.4).

No final do ano de 1890 Maria Augusta Meira de Vasconcelos concretizou o plano já sinalizado de candidatar-se a deputada no Congresso Nacional pelo Estado de Pernambuco. E aos eleitores apresentou suas intenções a serem executadas "se, por ventura, rompendo com os preconceitos, me confiardes tão nobre missão" (VASCONCELLOS, 1890b, p.3). Maria Augusta, no entanto, não logrou êxito em seu empreendimento político. 


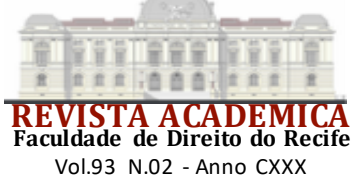

CARVALHO, J. Unificação da elite: uma ilha de letrados. In: CARVALHO, J. M. A construção da ordem: a elite política imperial. Teatro das sombras: a política imperial. 4a ed., p. 63-92. Rio de Janeiro: Civilização Brasileira, 2008.

CAVALCANTI, P. Eça De Queiroz: Agitador No Brasil. São Paulo: Companhia Editora Nacional, 1959.

COSTA, M. História do Direito Português. 5. ed. Coimbra: Almedina, 2019.

COSTA, M.; COSTA, R. Mulheres intelectuais na idade média: entre a medicina, a história, a poesia, a dramaturgia, a filosofia, a teologia e a mística. Porto Alegre: Editora Fi, 2019.

CUNHA, L. A universidade temporã: o ensino superior, da Colônia à Era Vargas. 3. ed. São Paulo: UNESP, 2007.

D'INCAO, M. Mulher e família burguesa. In: DEL PRIORE, M. (org.). História das mulheres no Brasil. 5. ed. São Paulo: Contexto, 2001.

DELGADO, J. A casa de Clóvis e de Andrade Bezerra. Recife: Universitária da UFPE, 2016.

DIARIO DE PERNAMBUCO. Recife, ano 122, n. 218, p.9, 18 de set. 1947. Disponível em: http://memoria.bn.br/DocReader/029033_12/27384. Acesso em: 13 mar. 2020.

DIARIO DE PERNAMBUCO. Recife, ano 64, n. 264, p.2, 18 nov. 1888b. Disponível em: http://memoria.bn.br/docreader/029033_06/21330. Acesso em: 19 mar. 2020.

DIARIO DE PERNAMBUCO. Recife, ano 64, n.12, p.4, 16 jan. 1890. Disponível em: http://memoria.bn.br/DocReader/029033_07/92. Acesso em: 22 abr. 2020.

DIARIO DE PERNAMBUCO. Recife, ano 64, n.261, p.3, 15 nov. 1888c. Disponível em: http://memoria.bn.br/DocReader/029033 06/21307. Acesso em: 16 abr. 2020.

DIARIO DE PERNAMBUCO. Recife, ano 71, n. 2, p. 3, 03 de jan. 1895. Disponível em: http://memoria.bn.br/DocReader/029033_07/10713. Acesso em: 17 mar. 2020.

DIARIO DE PERNAMBUCO. Recife, ano74, n.5, p.2, 08 de jan. 1898. Disponível em: http://memoria.bn.br/DocReader/029033_07/17848. Acesso em: 13 mar. 2020.

DIARIO DE PERNAMBUCO. Recife. ano 60, n. 51, p.4, 1 de mar. 1884. Disponível em: http://memoria.bn.br/DocReader/029033_06/10016. Acesso em: 20 abr. 2020.

DIARIO DE PERNAMBUCO. Recife. ano 64, n. 254, p.2, 7 nov. 1888a. Disponível em: http://memoria.bn.br/docreader/029033 06/21250. Acesso em: 30 abr. 2020.

DIARIO DO BRAZIL. Rio de Janeiro, ano 4, n.278, p.2, 2 de dez. 1884. Disponível em: http://memoria.bn.br/DocReader/225029/3781. Acesso em: 10 fev. 2020.

DRA. Maria Coelho. Gazeta de Noticias. Rio de Janeiro. ano 25, n.283, p.1, 10 de out. 1899.

Disponível em: http://memoria.bn.br/DocReader/103730_03/20712. Acesso em: 12 fev. 2020. 
ECO, U. Bettisia Gozzadini e Novella D’Andrea. In: ENCICLOPEDIA Delle Donne, s.d. Disponível em: http://www.enciclopediadelledonne.it/biografie/bettisia-gozzad ini-e-novelladandrea/. Acesso em: 25 mai. 2020.

FERREIRA, L. Maria Augusta Meira de Vasconcelos: a deputada que não foi. In: FERREIRA, L. Presença Feminina. Recife: Assembleia Legislativa do Estado de Pernambuco, 2002.

FITZGERAL, C. To Educate or Instruct? Du Bosc and Fénelon on Women. In: W. BARBARA J., ed., Women's Education in Early Modern Europe: a history, 1500-1800, p. 159-191. New York: Garland Publishing, 1999.

FORMADA em direito há 41 anos, foi a primeira mulher a praticar a advocacia no Brasil (1940, 21 de janeiro). Diario de Noticias. Rio de Janeiro, ano 10, n. 5287, p. 3, 6. Disponível em: http://memoria.bn.br/DocReader/093718_02/203. Acesso em: 30 jan. 2020.

FRAGOSO, M. A questão da mulher. A cultura acadêmica. Recife, ano 1, v.1, t. 1, fasc. 3, p.233-239, nov./dez.1904.

FREYRE, G. Vida social no Brasil nos meados do século XIX. Recife: Fundação Joaquim Nabuco, Editora Massangana, 2012.

FUNDAÇÃO JOAQUIM NABUCO (FUNDAJ). Coordenação-Geral de Estudos da História Brasileira (CEHIBRA). Microfilmagem. Recife Illustrado, ano 1, n. 13, 1888.

GAY, P. A experiência burguesa da Rainha Vitória a Freud: a educação dos sentidos. São Paulo: Companhia das Letras, 1988.

GUIMARÃES, L.; FERREIRA, T. Myrthes Gomes de Campos (1875-?): pioneirismo na luta pelo exercício da advocacia e defesa da emancipação feminina. Gênero, v. 9, n. 2, p. 135-151, 2009. Disponível em: https://periodicos.uff.br/revistagenero/article/view/30908/17997. Acesso em: 30 jun. 2020.

INSTITUTO DOS ADVOGADOS BRASILEIROS. Instituto dos Advogados Brasileiros: 150 Anos de história: 1843-1993. Rio de Janeiro: Destaque, 1995. Disponível em: https://www.iabnacional.org.br/biblioteca/e-book/e-book-do-iab. Acesso em: 20 maio 2020.

INSTITUTO NACIONAL DE ESTUDOS E PESQUISA EDUCACIONAIS ANÍSIO TEIXEIRA (INEP). Censo da Educação Superior 2018: notas estatísticas, 2019. Disponível em:

http://download inep.gov.br/ed ucacao_superior/censo_superior/documentos/2019/censo_da_educ acao_superior_2018-notas_estatisticas.pdf. Acesso em: 16 mar. 2020.

JORNAL DO RECIFE. Recife, ano 32, n. 264, p.1. 20 nov. 1889. Disponível em: http://memoria.bn.br/DocReader/705110/27707. Acesso em: 12 fev. 2020.

JORNAL DO RECIFE. Recife, ano 39, n. 183, p. 3, 13 ago. 1896. Disponível em: http://memoria.bn.br/DocReader/705110/37116. Acesso em: 10 abr. 2020.

JORNAL PEQUENO. Recife, ano 6, n. 179, p. 2, 10 ago. 1904. Disponível em: http://memoria.bn.br/DocReader/800643/7261. Acesso em: 14 abr. 2020. 
SALÃO nobre da Faculdade de Direito é reaberto. NE 10. 03 out. 2011. Disponível em: https://jconline.ne10.uol.com.br/canal/cidades/geral/noticia/2011/10/03/salao-nobre-dafaculdade-de-direito-e-reaberto-17772.php. Acesso em: 23 fev. 2020.

SCHUMAHER, S; BRAZIL, E. Dicionário das Mulheres do Brasil: de 1500 até a atualidade biográfico e ilustrado. Rio de Janeiro: Zahar, 2000. Disponível em: https:/guiad eturismornsite.files.word press.com/2017/02/dicionario-mulheres-d o-brasil-schumaschumaher.pdf. Acesso em: 22 fev. 2020.

SEXO FEMININO. Rio de Janeiro. ano 3, n. 3, p. 4, 16 jun. 1889. Disponível em: http://memoria.bn.br/DocReader/706868/276. Acesso em: 19 mar. 2020.

TEMPO e História: Jurista Bernadette Pedrosa é a Homenageada do Programa [S. 1.: s. n.], 2018. 1 vídeo (29 min). Publicado pelo canal Tv Justiça, 2018. Disponível em:

https://www.youtube.com/watch?v=EFd7PxDPqE8. Acesso em: 11 mar. 2020.

TIMOTHEO, P. A advocacia feminina no Brasil. Jornal do Brasil. Rio de Janeiro, ano 54, n. 302, p. 5, 22 dez. 1944. Disponível em: http://memoria.bn.br/docreader/030015_06/31101. Acesso em: 10 mar. 2020.

TRINDADE, A.; TRINDADE, D. Desafios das primeiras médicas brasileiras. História da Ciência e Ensino: construindo interfaces, v. 4, p. 24-37, 2011. Disponível em: https://revistas.pucsp.br/hcensino/article/view/6435. Acesso em: 17 mar. 2020.

UM CONSELHO. A Lanceta, Pernambuco, ano 2, n. 39, p. 4.26 abr. 1890. Disponível em: http://memoria.bn.br/DocReader/215244/148. Acesso em: 13 fev. 2020.

UNIVERSIDADE FEDERAL DE PERNAMBUCO. Arquivo Faculd ade de Direito do Recife. Curiosidades. Bernadete Pedrosa, a primeira mulher a ser admitida como professora da Faculdade de Direito do Recife em 1965, 2020c. Disponível em: https://www.ufpe.br/arquivoccj/curiosidades/-/asset_publisher/x1R6vFfGRYss/content/1965primeira-professora-de-direito-no-recife/590249. Acesso em: 17 mar. 2020.

UNIVERSIDADE FEDERAL DE PERNAMBUCO. Centro de Ciências Jurídicas. Escolaridade da Faculdade de Direito do Recife. Relatório de discentes ativos vinculados ao CCJ, [Recife: UFPE], 2020a.

UNIVERSIDADE FEDERAL DE PERNAMBUCO. Centro de Ciências Jurídicas. Escolaridade da Faculdade de Direito do Recife. Relatório de docentes ativos vinculados ao CCJ. [Recife: UFPE], 2020b.

VASCONCELLOS, M. Circular. Jornal do Recife. Recife, ano 33, n. 187 p. 2, 19 ago. 1890 b. Disponível em: http://memoria.bn.br/DocReader/705110/28628. Acesso em: 25 maio 2020.

VASCONCELLOS, M. Uma decisão injusta. Jornal de Recife. Recife, ano 33, n. 93, p. 2, 25 abr. 1890a. Disponível em: http://memoria.bn.br/DocReader/705110/28244. Acesso em: 26 mai. 2020.

VEIGA, G. História das ideias da Faculdade de Direito do Recife. 8. v. Recife: Artgraf, 1997. 


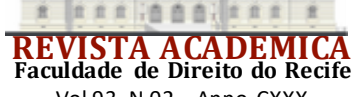

Vol.93 N.02 - Anno CXXX

WOLKMER, A. História do direito no Brasil. 6. ed. Rio de Janeiro: Forense, 2012. 